\title{
Approach to Primary Immunodeficiencies for the Non-Immunologist Physicians
}

\author{
García-López Carlos Alberto수, Alcázar-Casarín Emmanuel1, Ynga-Durand Mario Alberto1, \\ Alonso-Bello César Daniel1, Lozano-Patiño Fernando1, Vargas-Camaño María Eugenia1, \\ Espinosa-Padilla Sara Elva2 ${ }^{2}$, González-Serrano Maria Edith ${ }^{2}$, Castrejón-Vázquez María Isabel ${ }^{1}$ \\ ${ }^{1}$ Clinical Immunology and Allergy Department, National Médical Center “20 de Noviembre”, ISSSTE, Mexico City, México \\ ${ }^{2}$ Immunodeficiencies Research Unit, Instituto Nacional de Pediatria, Secretaría de Salud, Mexico City, México \\ Email: cesar_alonso86@hotmail.com
}

How to cite this paper: Alberto, G.-L.C., Emmanuel, A.-C., Alberto, Y.-D.M., Daniel, A.-B.C., Fernando, L.-P., Eugenia, V.-C.M., Elva, E.-P.S., Edith, G.-S.M. and Isabel, C.-V.M. (2019) Approach to Primary Immunodeficiencies for the Non-Immunologist Physicians. Open Access Library Journal, 6: e5419.

https://doi.org/10.4236/oalib.1105419

Received: April 22, 2019

Accepted: May 17, 2019

Published: May 20, 2019

Copyright $\odot 2019$ by author(s) and Open Access Library Inc.

This work is licensed under the Creative Commons Attribution International License (CC BY 4.0).

http://creativecommons.org/licenses/by/4.0/

\begin{abstract}
Introduction: Primary immunodeficiencies are a spectrum of diseases that encompasses alteration of the innate and adaptive immune response. Isolated lymphocytopenia may be a manifestation of primary immunodeficiency, which is rarely considered as a diagnostic option by non-immunological physicians. Objectives: To conduct a brief review of the primary immunodeficiencies that are most frequently associated with lymphocytopenia in order to provide a resource that will help non-immunological clinicians to recognize and appropriately refer to these cases. Materials and Methods: Review of the literature with scientific articles indexed in English and Spanish. We consulted Pubmed database with the keywords: primary immunodeficiencies and severe combined immunodeficiencies. The limit of time was 5 years and only review papers. Results: The search in the database results in 68 papers and we analyzed 35 articles because the objective of the review was Severe Combined Immunodeficiencies. Discussion: Persistent lymphopenia (usually $<2500$ $\mathrm{xmm}^{3}$ ) detected in blood cell cytometry that accompanies severe, recurrent infections, autoimmune manifestations, atopy and cancer may suggest severe combined immunodeficiency. Causes of secondary immunodeficiency such as HIV should be ruled out. Conclusions: Persistent lymphopenia can be associated with severe combined immunodeficiency. The study should be extended in these cases by a specialist or refer the patient to a referral center for a complete evaluation.
\end{abstract}

\section{Subject Areas}

Allergy \& Clinical Immunology

\section{Keywords}

Primary Immunodeficiencies, Immunodeficiency, Approach, Lymphopenia 


\section{Introduction}

The immune system is made up of cellular and humoral elements which constitute a mechanism of recognition between what is proper and what is foreign. Academically components of innate and adaptive immunity are distinguished as part of this; however, the connection between these mechanisms that make up a complex puzzle is increasingly understood, where it is enough that one of its participants is dysfunctional to interfere in other ways, leading with it to an imbalance and as a result an abnormal function, which may be greater or less than expected. The field of clinical immunology is dedicated to studying the alterations in the recognition and processing of own and external antigens, which constitutes four large groups of diseases, having as a central element of them the immune response (Figure 1).

\section{Objective}

To conduct a brief review of the primary immunodeficiencies that are most frequently associated with lymphocytopenia in order to provide a resource that will help non-immunological clinicians to recognize and appropriately refer these cases.

\section{Material and Methods}

Review of the literature with scientific articles indexed in English and Spanish. We consulted Pubmed database with the keywords: primary immunodeficiencies and severe combined immunodeficiencies combined de terms with AND, OR and NOT. The limit of time was 5 years and only reviewed papers about humans since January 2014 to January 2019 (Figure 2).

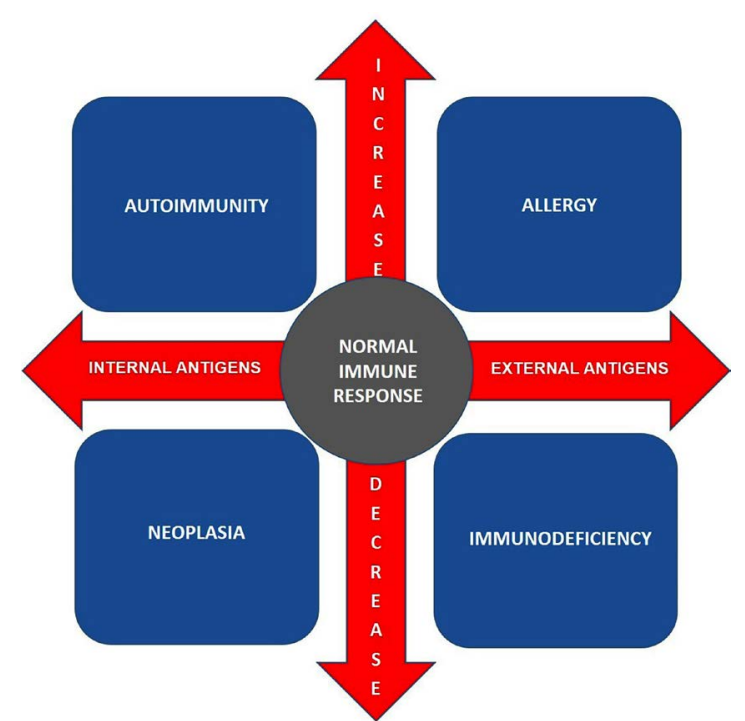

Figure 1. Diseases resulting from alterations in the immune response. The increase of the normal immune response leads to an allergy response or autoimmunity. The decrease of the immune response towards internal antigens will result in neoplasms and in antigens external to immunodeficiency. 


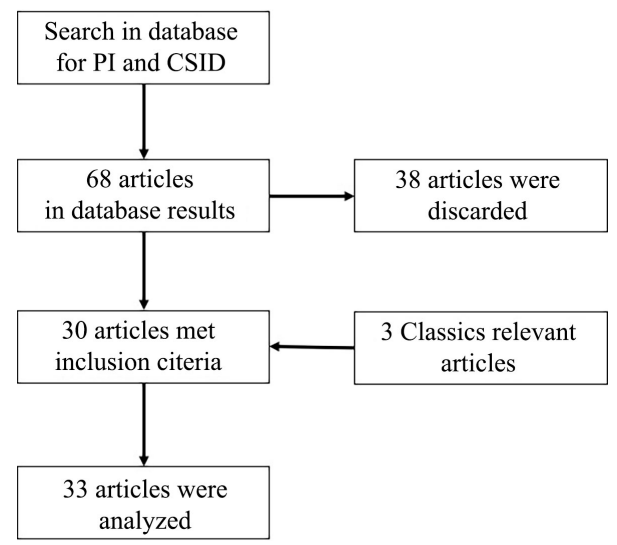

Figure 2. Flow diagram of the search strategy.

\section{Results}

The search in the database results in 68 papers and we analyzed 30 articles because the objective of the review was Severe Combined Immunodeficiencies. The variables to analyze were diagnosis, treatment and prognosis. 38 articles were discarded because they did not complain with the main topic of this review. We decided include two classics for the relevance for the population of our country and the classic article for the reference values.

\section{Discussion}

\subsection{Primary Immunodeficiencies}

The scientific advance in the field of basic and clinical immunology has made it possible to understand the behavior of many diseases; such the case of immunodeficiencies. Their basic classification divides them into primary (condition resulting from alterations in those genes and/or their products responsible for orchestrating the immune response) or secondary (external causes that lead to a state of transient or permanent immunosuppression). Derived from this classification, we know that primary immunodeficiencies (PID) are a heterogeneous group of diseases that originate from alterations in some of the components of the immune system. The PID are characterized mainly by a decrease in the response to external antigens, usually manifest from early stages of life or else once the individual is exposed to aggressing agents from microorganisms (external antigens). The PID can trigger the formation of internal antigens which can also become susceptible to trigger a response and thus the onset of autoimmunity [1]. In contrast to other hereditary diseases, these alterations may not be so evident at birth, which complicates their timely detection and treatment. The most evident manifestation of primary immunodeficiencies is the presence of recurrent or severe infections due to the decrease in the immune response, to which alterations can be added such as the presence of autoimmunity, lymphoproliferation, granulomatous processes, atopy, malignancy or the combination of them. These diseases have been classically described as the result of mutations in genes responsible for intervening in some step of the immune response, which in- 
cludes alterations in the proliferation of hematopoietic stem cells, development, maturation and cell proliferation specialized adaptive immunity (B cells and $\mathrm{T}$ cells), that includes processing and presentation of antigens, signaling and recognition of molecules and cytokines, functional disorders of cells (cell migration, respiratory burst, production of cytokines and chemotactic factors), regulation and resolution of the the response. The alterations of the components of innate immunity includes phagocytic-mononuclear system (macrophages and neutrophils), dendritic cells, complement and natural killer cells [1] [2].

Although immunodeficiencies can function as a model of monogenic diseases, the clinical expression of the disease usually involves more than a single component or altered pathway. There are, to date, more than 300 known primary immunodeficiencies and probably over the years the scientific advance in medicine will increase exponentially [3]. It is relevant to know that there are specialized centers in our country for the detection and treatment of these diseases. However, many times the diseases are diagnosed late and can culminate in death and a family tragedy. The most useful tools for the recognition of these entities are the exhaustive clinical history and basic laboratory tests that can be found in an affordable way in hospital units, such as a blood cell count, culture test for infectious agents, serum protein electrophoresis, serum immunoglobulins and imaging studies during the first part of the study. The second part of the study corresponds to specialists in clinical immunology and immunodeficiencies as well as specialized centers for the care of these diseases. That includes phenotypic and genetic study of PID, specialized and supportive therapies, family counseling and provide a definitive treatment [4]. This work aims to conduct a brief review of cellular immunodeficiencies that allow clinicians to guide the suspicion and approach of this complex disease.

Diseases resulting from alterations in the immune response. The increase of the normal immune response leads to an allergy response or autoimmunity. The decrease of the immune response towards internal antigens will result in neoplasms and in antigens external to immunodeficiency.

\subsection{Classification of Primary Immunodeficiencies}

Fundenberg, and cols. auspiced by the World Health Organization classified the primary immunodeficiencies. Their initial report identified 16 distinct immunodeficiencies. In 1999, the Committee on Primary Immunodeficiencies came under the auspices of the International Union of Immunological Societies (IUIS) [5]. Based on the genetic defect (genotype), the type of infections, the accompanying manifestations and the resulting clinical expression (phenotype), the Expert Committee of the IUIS has defined nine major groups of PID with the aim of increasing awareness, recognition and treatment of these entities [6] [7] (Figure 3).

Patients with PID show alterations in the response due to a decrease in the number or function of their components, which may exist at the level of innate 
immunity (complement, phagocytic-mononuclear system, cytotoxic cells, dendritic cells, etc.) and adaptive immunity (T lymphocytes, B lymphocytes and regulatory cells). This classification is practical and allows guiding in the first instance where the problem is. This imbalance will condition the lack of control in the response to other levels. Despite that in the majority of cases the cause of the disease is a monogenic defect, the immunological phenotype and therefore the clinical expression are very variable.

\subsection{Clinical Findings of the Most Frequent Primary Immunodeficiencies}

By January 2016, globally, humoral immunodeficiencies (antibody deficiencies) occupy the first place; that includes Latin American countries and Mexico, according to reports from the Latin American immunodeficiency society. On the other hand, cellular immunodeficiencies occupy between $9 \%$ and $10.5 \%$ of the immunodeficiencies worldwide within the PID; with an incidence of 1:50,000 100,000 live births [8] [9]. They are a heterogeneous group of immunodeficiencies and share a decrease in the count or function of $\mathrm{T}$ lymphocytes, which may be accompanied by antibody deficiencies (humoral) being called in these cases combined immunodeficiencies; in most cases this is due to lack of cooperation between $\mathrm{B}$ and $\mathrm{T}$ lymphocytes. Immunodeficiencies involving $\mathrm{T}$ lymphocytes (combined immunodeficiencies, combined severe and combined syndromes) are classified based on the presence or absence of lymphopenia and syndromic manifestations companions (Figure 4). Those PID with severe phenotypes or syndromic findings like SCID, X-linked agammaglobulinemia, usually manifest in early stages, and may be from birth and during the first years of life when they are diagnosed (pediatric population); that is why we should always consider them in the context of a child with serious, recurrent infections, short stature, anemia, cytopenias among other data. On the other hand, there is a group of PID with milder phenotypes that could represent a serious problem from childhood, adolescents and adults, either due to lack of an accurate diagnosis or the evolution of the disease, such is the case of immunodeficiencies predominantly of antibodies (group 3). For example, the selective deficiency of secretory immunoglobulin A (IgA), deficiency of subclasses of IgG, common variable immunodeficiency, or non-severe or severe combined immunodeficiencies such as lymphopenia of CD4 + cells (known as idiopathic CD4 + lymphocytopenia) due to alterations in MHC, CD8 + cells due to ZAP-70 deficiency, dendritic cell deficiency and variable common immunodeficiency. Depending on the level of the immune response, the patient can manifest infections that can help with suspicion within the diagnostic approach (Table 1) [10]. On the other hand, there are other clinical and paraclinical manifestations present with a greater frequency in these types of primary immunodeficiency comparatively with the healthy population: such is the case of autoimmune, allergic neoplastic/lymphoproliferative manifestations, which can increase the degree of suspicion. 
Table 1. Microorganisms most frequently associated with primary immunodeficiencies based on altered pathway.

\begin{tabular}{|c|c|c|c|c|}
\hline Microorganism & Antibody Deficiency & Combined (cells + antibodies) & Phagocytosis defects & $\begin{array}{l}\text { Complement deficien- } \\
\text { cies }\end{array}$ \\
\hline Virus & $\begin{array}{l}\text { Enterovirus }(\mathrm{X} \text {-linked } \\
\text { agammaglobulinemia) }\end{array}$ & $\begin{array}{l}\text { Anyone. } \\
\text { More frequent CMV, RSV, EBV (combined) } \\
\text { papillomavirus, Herpes virus (NK cells) }\end{array}$ & No & No \\
\hline Bacterias & $\begin{array}{l}\text { Streptococcus pneumoniae, } \\
\text { Haemophilus influenzae, } \\
\text { Moraxella catarrhalis, } \\
\text { Pseudomonas aeruginosa }\end{array}$ & $\begin{array}{l}\text { Streptococcus pneumoniae, } \\
\text { Haemophilus influenzae, } \\
\text { Moraxella catarrhalis, } \\
\text { Pseudomonas aeruginosa, Salmonella typhi, } \\
\text { Listeria monocytogenes } \\
\text { Yersinia } \\
\text { Campylobacter }\end{array}$ & $\begin{array}{l}\text { Staphylococcus aureus, } \\
\text { Burkholderia cepacia, } \\
\text { Nocardia, Serratia }\end{array}$ & $\begin{array}{l}\text { Streptococcus } \\
\text { pneumoniae, } \\
\text { Haemophilus influenzae, } \\
\text { Moraxella catarrhalis, } \\
\text { Pseudomonas aeruginosa, } \\
\text { Neisseria meningitidis } \\
\text { Haemophilus influenzae } \\
\text { (C5-C9 deficiency) }\end{array}$ \\
\hline Mycobacterias & No & Non-tuberculous including BCG & $\begin{array}{l}\text { Non-tuberculous } \\
\text { including BCG }\end{array}$ & No \\
\hline Fungus & No & $\begin{array}{l}\text { Candida, } \\
\text { Aspergillus, } \\
\text { Cryptococcus, } \\
\text { Histoplasma capsulatum Cryptosporidium }\end{array}$ & $\begin{array}{l}\text { Candida, } \\
\text { Aspergillus }\end{array}$ & No \\
\hline Protozoan & Giardia lamblia & $\begin{array}{l}\text { Pneumocystis jiroveci, } \\
\text { Toxoplasma, Cryptosporidium parvum }\end{array}$ & No & No \\
\hline
\end{tabular}

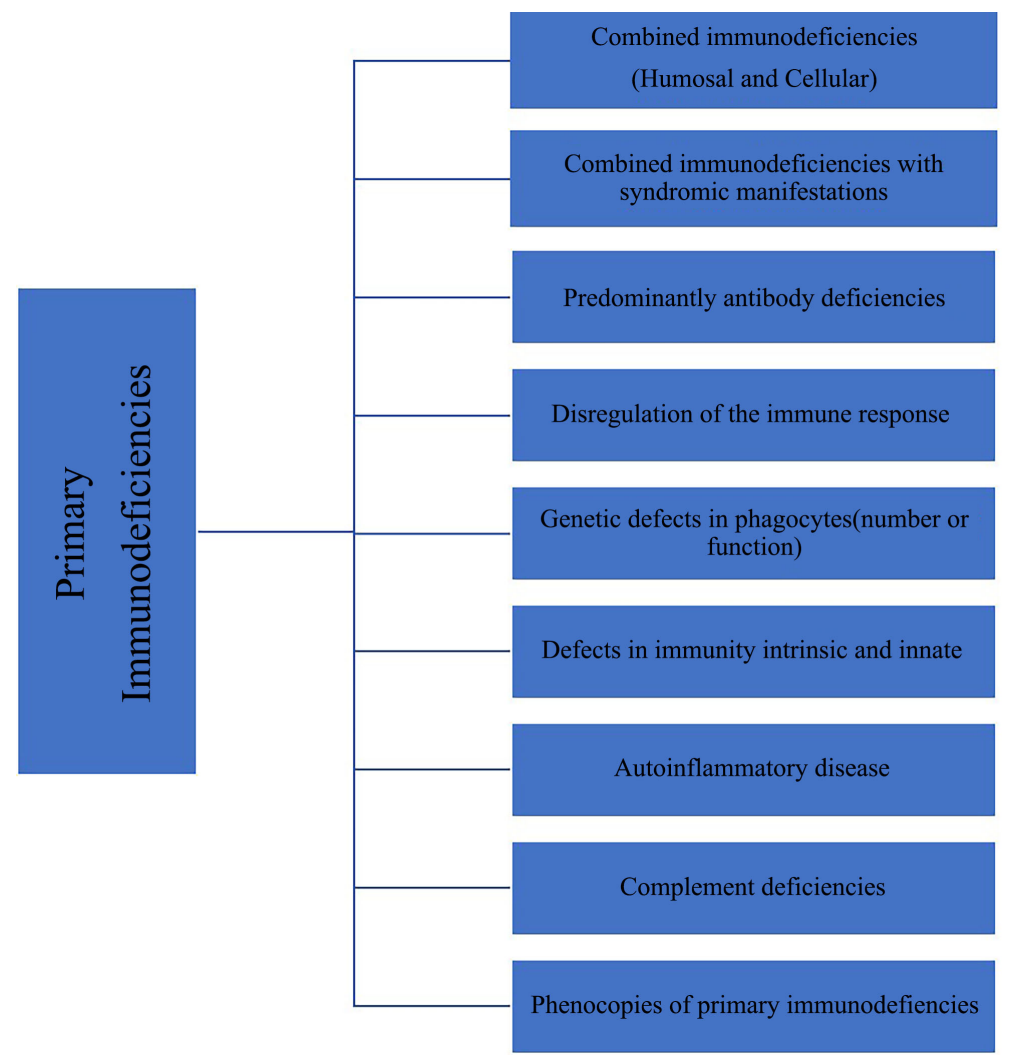

Figure 3. Classification of primary immunodeficiencies according to the latest report of the International Union of the Committee of Experts of Societies of Immunology for Primary Immunodeficiencies or IUIS for their figures in English (International Union of Immunological Societies Expert Committee for Primary Immunodeficiency) [5]. 


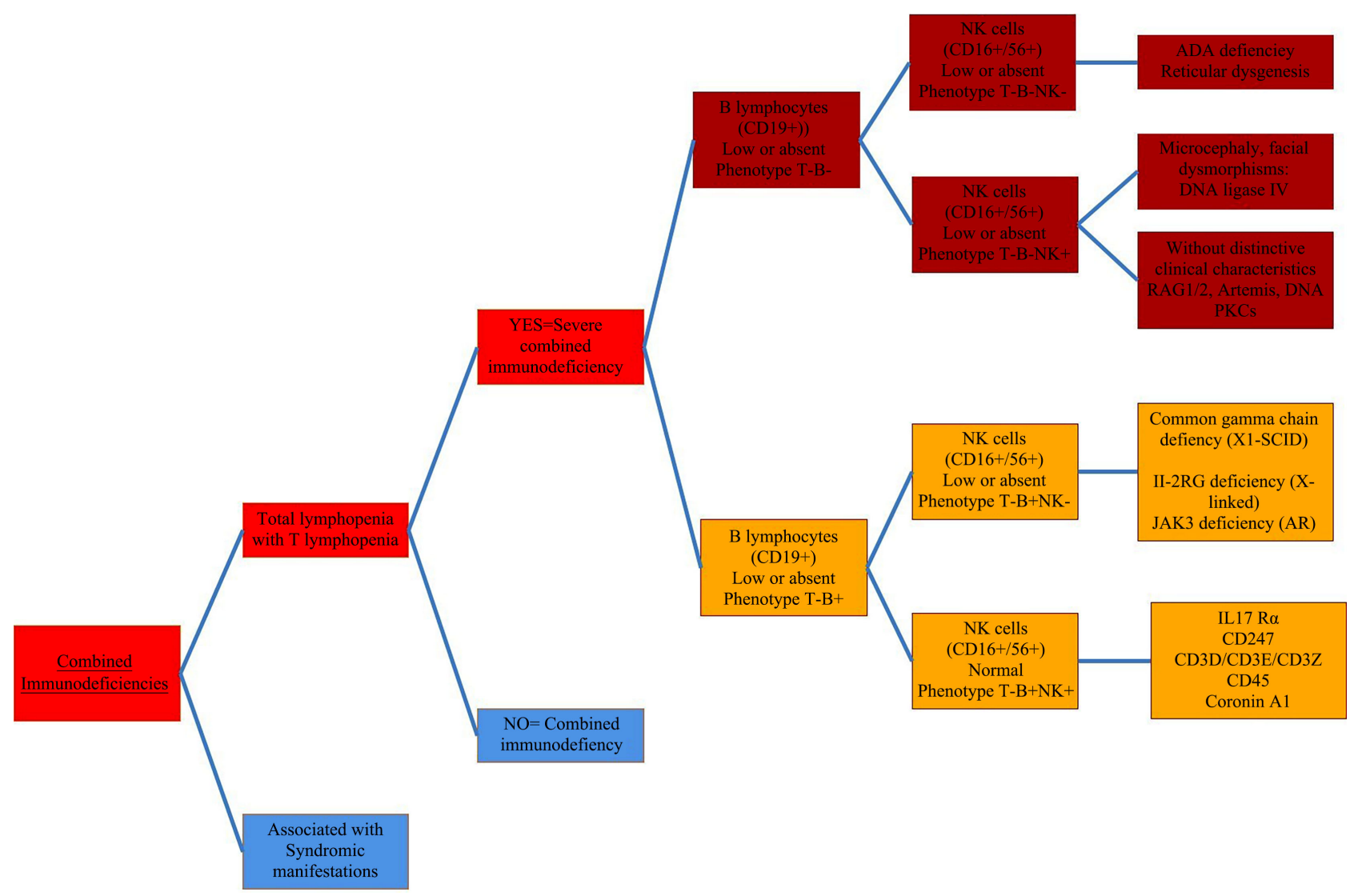

Figure 4. Classification of severe combined immunodeficiency according to consensus of the International Union of the Committee of Experts of Societies of Immunology for Primary Immunodeficiencies.

\subsection{Lymphopenia as a Part of the Diagnosis of IDCS and Differential Diagnosis}

Cytometry or blood biometry is the principal tool useful for diagnosis. Before declaring a patient with lymphopenia, we must know the ranges of percentile lymphocytes for age (Table 2) since these values change as the years pass and determine if it really corresponds to lymphopenia. The lymphocyte count in the case of SCID persists low over time or is slightly modified, considering as a general reference point a total lymphocyte count less than $2500 \mathrm{xmm}^{3}$ abnormal. The parameters that should be evaluated in the context of suspicion are the total count of leukocytes and lymphocytes (cells x cubic millimeter) in the blood cytometry, as well as the total count of $\mathrm{T}$ lymphocytes (70\% of the total lymphocyte population) and its subpopulations (CD3+, $\mathrm{CD} 4+, \mathrm{CD} 8+$, ratio CD4+/CD8+), number of B lymphocytes (CD19+ CD20+, $20 \%$ to $30 \%$ of total lymphocytes) and natural killer cells (NK CD16+56+) as well as the titles of immunoglobulins G, A, M (milligrams/dl) and E (UI/L) percentiles for age (Table 3). The definitive diagnosis is made with the determination of the mutation associated with the defect, however this should not be a condition for delaying treatment so it is a priority to send a specialist or reference center in immunodeficiencies when the suspicion is elevated. 
Table 2. Total lymphocyte ranges and T-cell lymphocyte subpopulations based on age of healthy population (percentiles 5 to 95). Modified from "Immunophenotyping of blood lymphocytes in childhood. Reference values for lymphocyte subpopulations. Modified from Comans-Bitter WM et al. [17]. Values expressed in cells per cubic millimeter of blood (cells $\times \mathrm{mm}^{3}$ ). $\mathrm{RN}=\mathrm{Newborn}$. $\mathrm{s}$ $=$ weeks. $\mathrm{m}=$ months. $\mathrm{a}=$ years. $\mathrm{T}=\mathrm{T}$ cells. $\mathrm{NK}=$ Natural killer cells. $\mathrm{B}=\mathrm{B}$ cells.

\begin{tabular}{|c|c|c|c|c|c|c|c|c|c|c|}
\hline Lymphocytes & $\mathrm{RN}$ & $1 s-2 m$ & $2-5 m$ & $5-9 m$ & $9-15 m$ & $15-24 m$ & $2-5 a$ & $5-10 a$ & $10-16 a$ & $>16 a$ \\
\hline Absolutes & $700-7300$ & $3500-13,100$ & $3700-9600$ & $3800-9900$ & $2600-10,400$ & $2700-11,900$ & $1700-6900$ & $1100-5900$ & $1000-5300$ & $1000-2800$ \\
\hline $\mathrm{CD} 3+\mathrm{T}$ & $600-5000$ & $2300-7000)$ & $2300-6500$ & $2400-6900$ & $1600-6700$ & $1400-8000$ & $900-4500$ & $700-4200$ & $800-3500$ & $700-2100$ \\
\hline $\mathrm{CD} 4+\mathrm{T}$ & $400-3500$ & $1700-5300$ & $1500-5000$ & $1400-5100$ & $1000-4600$ & $900-5500$ & $500-2400$ & $300-2000$ & $400-2100$ & $300-1400$ \\
\hline $\mathrm{CD} 8+\mathrm{T}$ & $200-1900$ & $400-1700$ & $500-1600$ & $600-2200$ & $400-2100$ & $400-2300$ & $300-1600$ & $300-1800$ & $200-1200$ & $200-900$ \\
\hline $16 / 56 \mathrm{NK}$ & $100-1900$ & $200-1400$ & $100-1300$ & $100-1000$ & $200-1200$ & $100-1400$ & $100-1000$ & $90-900$ & $70-1200$ & $90-600$ \\
\hline $\mathrm{CD} 19+\mathrm{B}$ & $40-1100$ & $600-1900$ & $600-3000$ & $700-2500$ & $600-2700$ & $600-3100$ & $200-2100$ & $200-1600$ & $200-600$ & $100-500$ \\
\hline
\end{tabular}

Table 3. Serum immunoglobulin ranges based on age, healthy population (percentiles 5 to 95). Modified from Jollif CR et al. [18]. IgG = immunoglobulin G. IgM = Immunoglobulin M. IgA = Immunoglobulin A. mg/dL = milligrams per deciliter.

\begin{tabular}{|c|c|c|c|c|c|c|c|c|c|c|c|c|c|}
\hline Age & $\mathrm{RN}$ & $1 \mathrm{~m}$ & $2 \mathrm{~m}$ & $3 \mathrm{~m}$ & $4 \mathrm{~m}$ & $5 \mathrm{~m}$ & $6 \mathrm{~m}$ & $7-9 \mathrm{~m}$ & $10-12 \mathrm{~m}$ & $2 a$ & $3 a$ & $4-5 a$ & $6-8 a$ \\
\hline $\begin{array}{c}\mathrm{IgG} \\
\mathrm{mg} / \mathrm{dL}\end{array}$ & $636-1606$ & $251-906$ & $206-601$ & $176-581$ & $196-558$ & $172-814$ & $215-704$ & $217-904$ & $294-1069$ & $424-1051$ & $441-1135$ & $463-1236$ & $633-1280$ \\
\hline $\begin{array}{c}\mathrm{IgM} \\
\mathrm{mg} / \mathrm{dL}\end{array}$ & $6.3-25$ & $20-87$ & $17-105$ & $24-89$ & $27-101$ & $33-108$ & $35-102$ & $34-126$ & $41-149$ & $48-168$ & $47-200$ & $43-196$ & $48-207$ \\
\hline $\begin{array}{c}\text { IgA } \\
\mathrm{mg} / \mathrm{dL}\end{array}$ & $1.4-3.6$ & $1.3-53$ & $2.8-47$ & $4.6-49$ & $4.4-73$ & $8.1-84$ & $8.1-68$ & $11-90$ & $16-84$ & $14-123$ & $22-159$ & $25-154$ & $33-202$ \\
\hline Age & $\mathrm{RN}$ & $1 \mathrm{~m}$ & $2 \mathrm{~m}$ & $3 \mathrm{~m}$ & $4 \mathrm{~m}$ & $5 \mathrm{~m}$ & $6 \mathrm{~m}$ & $7-9 m$ & $10-12 \mathrm{~m}$ & $2 \mathrm{a}$ & $3 \mathrm{a}$ & $4-5 a$ & $6-8 a$ \\
\hline $\begin{array}{c}\text { IgG } \\
\mathrm{mg} / \mathrm{dL}\end{array}$ & $636-1606$ & $251-906$ & $206-601$ & $176-581$ & $196-558$ & $172-814$ & $215-704$ & $217-904$ & $294-1069$ & $424-1051$ & $441-1135$ & $463-1236$ & $633-1280$ \\
\hline $\begin{array}{c}\mathrm{IgM} \\
\mathrm{mg} / \mathrm{dL}\end{array}$ & $6.3-25$ & $20-87$ & $17-105$ & $24-89$ & $27-101$ & $33-108$ & $35-102$ & $34-126$ & $41-149$ & $48-168$ & $47-200$ & $43-196$ & $48-207$ \\
\hline $\begin{array}{c}\operatorname{IgA} \\
\mathrm{mg} / \mathrm{dL}\end{array}$ & $1.4-3.6$ & $1.3-53$ & $2.8-47$ & $4.6-49$ & $4.4-73$ & $8.1-84$ & $8.1-68$ & $11-90$ & $16-84$ & $14-123$ & $22-159$ & $25-154$ & $33-202$ \\
\hline
\end{tabular}

Always consider discarding secondary immunodeficiencies (malnutrition, human immunodeficiency virus infection), neoplasms, use of immunosuppressants as part of the treatment of autoimmunity and cancer, radiotherapy, to discuss the main ones. A point to be highlighted in the differential diagnosis are autoimmune diseases (systemic lupus erythematosus, primary Sjögren's syndrome, systemic vasculitis, rheumatoid arthritis, autoimmune cytopenias); although they should be considered as part of the differential diagnoses, primary immunodeficiencies with autoimmune manifestations are increasingly known, so in these cases it will be preferable to refer the patient to complete the study [11] [12]. Finally, there is a neonatal screening method, determination of TRECs (T-cell receptor excision circle assay) for early detection in patients with risk factors for severe combined immunodeficiencies which have shown very good results [13]. This method is also performed in the immunodeficiency research laboratory of the National Institute of Pediatrics (INP). 


\subsection{Severe Combined Immunodeficiencies}

They represent a heterogeneous group of diseases that are characterized by decreased response dependent $\mathrm{T}$ cells $(\mathrm{CD} 3$ + lymphocytopenia), either by number, function or both. The most common form worldwide is caused by defects in the common gamma chain, which is transmitted with X-linked inheritance, with a variable prevalence in $50 \%$ to $80 \%$ of severe combined immunodeficiencies reported in several countries. It should be sought intentionally in men in the early stages of life with a history of direct male relatives who died at an early age due to serious infections or both genders for the case of autosomal recessive inheritance, although there may be de novo mutations without family background. When there are antecedents of consanguinity, forms with autosomal recessive inheritance should be sought. Usually, in the majority of cases, growth failure, absence of lymphoid tissues (tonsils and lymph nodes), chronic diarrhea of infectious characteristics, develop in the first weeks of life [14] [15] [16]. In the particular case of syndromic combined immunodeficiency, inflammatory dermatological lesions (maculopapularrash, persistent warts, molluscumcontagiosum, atypical or severe eczema, seborrheic dermatitis and cellulitis) are the clinical findings. There may be cases where the course of the first weeks of life is normal. The presence of lymphocytopenia, usually less than $2500 \mathrm{xmm}^{3}$, is absent in late skin tests such as PPD or candidin, (Type IV hypersensitivity depends on $\mathrm{T}$ cells), variable degrees of hypogammaglobulinemia, and failure of proliferation tests with mitogens (phytohemagglutinin) and eosinophilia. The lesions reported in Mexico after BCG vaccination can be of various forms, from infiltrating and ulcerated lesions at the site of application, regional lymphadenopathies, violaceous systemic papular skin lesions, osteolytic lesions, dissemination to spleen, liver, lung and ganglia. In these cases antifungal treatment should be initiated or prophylaxis should be given when there is a history of application of the vaccine without clinical manifestations. It is convenient to corroborate the results of the blood count with a second dose and compare the values with those corresponding to age, before initiate a diagnostic approach [19] [20] [21] [22].

\subsection{Reference Criteria}

Patients who have the clinical and laboratory characteristics that make the suspicion of severe combined immunodeficiency should be referred to a specialized center for its diagnostic and treatment that includes the support aspect (nutritional, hematological and infectious) or definitive, such as hematopoietic stem cell transplantation, because the success of this depends whether it is carried out within the first three months of vida. There are internationally accepted points that function as alarm data to suspect immunodeficiencies. The following clinical criteria should be considered as relevant data for CSID [19] [20] [21] [22] [23].

1) Clinical criteria: 
- Delay in growth and weight gain

- Early deaths in related relatives of infectious or poorly understood causes, men in the case of inheritance linked to $\mathrm{X}$ and both sexes for autosomal recessive inheritance.

- Antecedent of consanguinity (autosomal recessive)

- Recurrent or severe infections, early hospitalizations, use of antimicrobials, antivirals, parenteral antifungals

- Chronic diarrhea

- Early dermatological manifestations

- Absence of tonsils and palpable lymph nodes (especially in association with upper and lower respiratory infections)

- Adverse reaction to vaccines (BCG, live attenuated virus)

2) Laboratory criteria:

- Microbiological isolation of microorganisms related to the disease

- Leukopenia with persistent lymphopenia less than 2500 cells $/ \mathrm{mm}^{3}$, considering strong suspicion with values less than $500 \mathrm{xmm}^{3}$ or below the 5 th percentile for age

- Absent lymphoproliferation with stimulation test with mitogens (phytohemagglutinins)

- Low levels of immunoglobulins G, A, M below the 5th percentile for age

- Absence of thymus in chest X-ray

- Negative tests with tuberculin and candidin antigens

\subsection{Initial Management}

Considering the suspicion of illness and should seek the assessment by a specialist or refer to a center specialized in immunodeficiencies. Starting a support treatment that includes relevant aspects for these patients allows us to improve their conditions so that in the near future they will be considered for a definitive treatment protocol. These measures should not be delayed to the definitive diagnosis, the clinical criterion and the experience should regulate these conducts. The main measures that should be considered in these cases are:

1) Use of intravenous human immunoglobulin: It is considered an absolute indication when there is a clear quantitative deficiency of IgG accompanied by recurrent and/or severe infections. The infusion should be done every 21 days at slow speed at a rate of $400-600 \mathrm{mg} / \mathrm{kg}$ per infusion. It is possible to increase to 1 - $2 \mathrm{~g} / \mathrm{kg}$ when infections are severe or accompany severe autoimmunity/inflammation manifestations [24]. Infusion should be carried out even after transplantation until immune reconstitution is documented.

2) Prophylaxis: Treatment should be provided that includes coverage for Pneumocystis jirovecci, fungi and if there is suspicion or sustainable justification for virus until definitive treatment is achieved. In children who have received BCG vaccine, antifungal treatment should be initiated in case of clinical manifestations or prophylaxis if it has not developed them. 
3) Family study of genes and genetic counseling for parents.

4) Blood products: In case of transfusion, requirements should be made with irradiated blood products to avoid possible complications such as graft-versus-host disease and transmission of potential infectious germs.

5) Immunizations: The health team and the relatives of the patient must be properly immunized. If combined immunodeficiency is suspected, immunizations with live and attenuated viruses should not be applied, as should BCG if possible [25] [26].

\subsection{Especialized Treatment}

Currently hematopoietic stem cell transplantation is considered the curative treatment of primary immunodeficiencies, there are well-established indications to perform this procedure. SCID is one of the main indications and it is known that there is improvement in $\mathrm{T}$ cell depletion as well as improvement in patient survival as long as it is performed before the onset of major complications such as repetitive infections and delay of growth. This type of treatment is carried out only by highly specialized medical units. [27] [28].

Another of the emerging treatments is gene therapy, whose purpose is the transfer of genetic material to reestablish a cellular function that is abolished or defective. This type of therapy was offered for the first time in the SCID. It has been successful thanks to its superiority in the processes of haematopoietic stem cell transplantation and the best conditioning therapies for patients, as well as better vectors. It could be used when the defective gene is known and it needs regulation. This type of therapy is a new therapeutic option for patients with IDP, however it is still under development [29] [30] [31] [32] [33].

\section{Conclusion}

Persistent lymphopenia at the expense of $\mathrm{T}$ cells can translate to severe combined immunodeficiency. It should be considered an emergency for study. Severe combined immunodeficiencies alter the development of $\mathrm{T}$ cells lead to functional or developmental alterations of other groups of lymphocytes such as B cells and NK cells. The most common severe combined immunodeficiency is caused by mutations in the common gamma chain receptor that shares several interleukin receptors, essential for the development and maturation of $\mathrm{T}$ and $\mathrm{NK}$ cells. It is transmitted with inheritance linked to X (affection of men). Initial treatment should not be delayed due to suspicion of CSID. The treatment includes antimicrobial prophylaxis and for tuberculosis if the patient was vaccinated, intravenous gamma globulin, transfusion of irradiated blood products to requirements, avoidance of vaccines with attenuated microorganisms. The definitive treatment in the majority of the combined severe immunodeficiencies is the transplantation of hematopoietic stem cells or gene therapy. Its success is partly due to being carried out in the early stages of life, preferably before 3 months of age. 


\section{Conflicts of Interest}

The authors declare no conflicts of interest regarding the publication of this paper.

\section{References}

[1] Ochs, H., Smith, E. and Puck, J. (2014) Primary Immunodeficiency Disease, a Molecular a Genetic Approach. 3th Edition, Oxford University Press, Oxford.

[2] Fischer, A. (2015) Recent Advances in Understanding the Pathophysiology of Primary T Cell Immunodeficiencies. Trends in Molecular Medicine, 21, 408-416. https://doi.org/10.1016/j.molmed.2015.04.002

[3] Raje, N. and Dinakar, C. (2015) Overview of Immunodeficiency Disorders. Immunology and Allergy Clinics of North America, 35, 599-623. https://doi.org/10.1016/j.iac.2015.07.001

[4] García-Cruz, M.L., Camacho, R., Ortega-Martell, J.A., Berrón-Pérez, R., Espinosa-Rosales, F., Hernández-Bautista, V., et al. (2002) Registry of Primary Immunodeficiencies in Mexican Patients in a Third-Level Institution: 30-Year Experience. Allergy, Asthma and Pediatric Immunology, 11, 48-66.

[5] Picard, C., Gaspar, H.B., Al-Herz, W., Bousfiha, A., Jean-Leurent, C. and Chatila, T., et al. (2018) International Union of Immunological Societies: 2017 Primary Immunodeficiency Diseases Committee Report on Inborn Errors of Immunity. Journal of Clinical Immunology, 38, 96-128. https://doi.org/10.1007/s10875-017-0464-9

[6] Picard, C., Al-Herz, W., Bousfiha, A., Casanova, J.L., Chatila, T., Conley, M.E., et al. (2015) Primary Immunodeficiency Diseases: An Update on the Classification from the International Union of Immunological Societies Expert Committee for Primary Immunodeficiency 2015. Journal of Clinical Immunology, 35, 696-726. https://doi.org/10.1007/s10875-015-0201-1

[7] Bousfiha, A., Jeddane, L., Picard, C., Ailal, F., Bobby Gaspar, H., Al-Herz, W., et al. (2018) The 2017 IUIS Phenotypic Classification for Primary Immunodeficiencies. Journal of Clinical Immunology, 38, 129-143. https://doi.org/10.1007/s10875-017-0465-8

[8] Latin American Society of Immunodeficiencies (2019) Statistics-Registration of IDPs. http://www.lasid.org

[9] Hernández-Blas, M., Orozco-Martínez, S., Contreras-Verduzco, A., Medina-Torres, E. and Espinosa-Padilla, S. (2014) When to Suspect Severe Combined Immunodeficiency in Children? Alergia, Asma e Inmunología Pediátricas. México, 23, 20-26.

[10] Lehman, H., Hernández-Trujillo, V. and Ballow, M. (2015) Diagnosings Primary Immunodeficiency: A Practical Approach for the Non-Immunologist. Current Medical Research and Opinion, 31, 697-706. https://doi.org/10.1185/03007995.2014.1001063

[11] Shearer, W., Dunn, E., Notarangelo, L., Dvorak, C., Puck, J., Logan, B., et al. (2014) Establishing Diagnostic Criteria for SCID, Leaky SCID, Ommen Syndrome: The primary Immune Deficiency Treatment Consortium Experience. The Journal of Allergy and Clinical Immunology, 133, 1092-1098. https://doi.org/10.1016/j.jaci.2013.09.044

[12] Marinovic, M.A. (2012) Immunodeficiencies and Their Relationship with Autoinmune Diseases. Revista Médica Clínica Las Condes, 23, 484-491. https://doi.org/10.1016/S0716-8640(12)70339-5 
[13] Olbrich, P., de Felipe B., Delgado-Pecellin, C., Rodero, R., Rojas, P., Aguayo, J., Marquez, J., Casanovas, J., Sánchez, B., Lucena, J.M., Ybot-Gonzalez, P., Borte, S. and Neth, O. (2014) A First Pilot Study on the Neonatal Screening of Primary Immunodeficiencies in Spain: TRECS and KRECS Identify Severe T- and B-Cell Lymphopenia. Anales de Pediatría, 81, 310-317. https://doi.org/10.1016/j.anpedi.2014.08.002

[14] Gaspar, H., Hammaström, L., Nahlaoui, N., Borte, M. and Borte, S. (2014) The Case for Mandatory Newborn Screening for Severe Combined Immunodeficiency (SCID). Journal of Clinical Immunology, 34, 393-397.

https://doi.org/10.1007/s10875-014-0029-0

[15] Biggs, C.M., Haddad, E., Issekuts, T.B., Roifman C.M. and Turvey, S.E. (2017) Newborn Screening for Severe Combined Immunodeficiencies: A Primer for Clinicians. Canadian Medical Association Journal, 189, E1551-E1557. https://doi.org/10.1503/cmaj.170561

[16] Pérez-Aguilar, M.C., Goncalves, L. and Bonfante-Cabarcas, R. (2012) Adenosin Deaminase in Severe Combined Immunodeficiency Syndrome. Investigación Clínica, 53, 315-324.

[17] Comans-Bitter, W.M., de Groot, R., van den Beemd, R., Neijens, H.J., Hop, W.C., Groeneveld, K., Hooijkaas, H., et al. (1997) Immunophenotyping of Blood Lymphocytes in Childhood. Reference Values for Lymphocyte Subpopulations. The Journal of Pediatrics, 130, 388-393. https://doi.org/10.1016/S0022-3476(97)70200-2

[18] Jollif, C.R., Cost, K.M., Stivrins, P.C., Grossman, P.P., Nolte, C.R., Franco, S.M., et al. (1982) Reference Intervals from Serum IgG, IgA, IgM, C3, C4 as Determined by Rate Nephelometry. Clinical Chemistry, 28, 126-128.

[19] Kwan, A. and Puck, J.M. (2015) History and Current Status of Newborn Screening for Severe Combined Immunodeficiency. Seminars in Perinatology, 39, 194-205. https://doi.org/10.1053/j.semperi.2015.03.004

[20] Diamond, C.E., Sanchez, M.J. and LaBelle, J.L. (2015) Diagnostic Criteria and Evaluation of Severe Combined Immunodeficiency in the Neonate. Pediatric Annals, 44, e181-e187. https://doi.org/10.3928/00904481-20150710-12

[21] Madkaikar, M., Aluri, J. and Gupta, S. (2016) Guidelines for Screening, Early Diagnosis and Management of Severe Combined Immunodeficiency (SCID) in India. The Indian Journal of Pediatrics, 83, 455-462. https://doi.org/10.1007/s12098-016-2059-5

[22] Cirillo, E., Giardino, G., Gallo, V., D’Assante, R., Grasso, F., Romano, R., et al. (2015) Severe Combined Immunodeficiency-An Update. Annals of the New York Academy of Sciences, 1356, 90-106. https://doi.org/10.1111/nyas.12849

[23] Buelow, B.J., Verbsky, J.W. and Routes, J.M. (2016) Newborn Screening for SCID: Lessons Learned. Expert Review of Hematology, 9, 579-584.

https://doi.org/10.1080/17474086.2016.1180243

[24] Berrón-Pérez, R., Espinosa-Rosales, F.J., Márquez-Aguirre, M.P., Sainos, A., Ivory, J., Selva-Pallares, J.E., et al. (2005) Expert Consensus on the Current Therapeutic Use of Intravenous Immunoglobulin. Revista Alergia México, 52, 42-50.

[25] Galicchio, M., Ornani, A., Bezrodnik, L., Di Giovanni, D., Gomez-Raccio, A., Paz, R., et al. (2010) Management Guidelines: Vaccines in Patients with Primary Immunodeficiencies. Archivos Argentinos de Pediatria, 108, 454-464.

[26] Sobh, A. and Bonilla, F.A. (2016) Vaccination in Primary Immunodeficiency Disorders. The Journal of Allergy and Clinical Immunology. In Practice, 4, 1066-1075. https://doi.org/10.1016/j.jaip.2016.09.012 
[27] Freeman, A.F. (2018) Hematopoietic Stem Cell Transplantation in Primary Immunodeficiencies beyond Severe Combined Immunodeficiency. Journal of the Pediatric Infectious Diseases Society, 7, S79-S82. https://doi.org/10.1093/jpids/piy114

[28] Heimall, J., Puck, J., Buckley, R., Fleisher, T.A., Gennery, A.R., Neven, B., et al. (2017) Current Knowledge and Priorities for Future Research in Late Effects after Hematopoietic Stem Cell Transplantation (HCT) for Severe Combined Immunodeficiency Patients: A Consensus Statement from the Second Pediatric Blood and Marrow Transplant Consortium International Conference on Late Effects after Pediatric HCT. Biology of Blood and Marrow Transplantation, 23, 379-387. https://doi.org/10.1016/j.bbmt.2016.12.619

[29] Touzot, F., Hacein-Bey-Abina, S., Fischer, A. and Cavazzana, M. (2014) Gene Therapy for Inherited Immunodeficiency. Expert Opinion on Biological Therapy, 14, 789-798. https://doi.org/10.1517/14712598.2014.895811

[30] Ghosh, S.G. and Gaspar, H.B. (2017) Gene Therapy Approaches to Immunodeficiency. Hematologyl Oncology Clinics of North America, 31, 823-834. https://doi.org/10.1016/j.hoc.2017.05.003

[31] Fischer, A., Hacein-Bey Abina, S., Touzot, F. and Cavazzana, M. (2015) Gene Therapy for Primary Immunodeficiencies. Clinical Genetics, 88, 507-515. https://doi.org/10.1111/cge.12576

[32] Sauer, A.V., Di Lorenzo, B., Carriglio, N. and Aiuti, A. (2014) Progress in Gene Therapy for Primary Immunodeficiencies Using Lentiviral Vectors. Current Opinion in Allergy and Clinical Immunology, 14, 527-534. https://doi.org/10.1097/ACI.0000000000000114

[33] Kohn, D.B. and Kuo, C.Y. (2017) New Frontiers in the Therapy of Primary Immunodeficiency: From Gene Addition to Gene Editing. The Journal of Allergy and Clinical Immunology, 139, 726-732. https://doi.org/10.1016/j.jaci.2017.01.007 